concept of "primary" and "secondary" segments which cannot now be accepted should occupy such important cornors in Beklemishev's argument. He therefore uses terms such as "kinetoblast" and "phagocytoblast".

Yet there is much to be gained from a reading of these volumes. The comparative approach to the muscular systems, circulatory systems, reproductive organs and to the development of the colonial habit in diverse phyla is stimulating in the detail in which each comparison is made.

This is a book which every zoology department should have in its library. It is a mine of information, much of which is not readily available except in specialist texts or papers. It is well printed and produced, and the publishers are to be congratulated on making this work available in English.

R. P. Dalks

'Tiegs, O. W., and Manton, S. M., Biol. Rev., 33, 255 (1958).

2 Anderson, D. T... Acta Zool., 47, 1 (1966).

${ }^{3} \AA$ kesson, B., Ark. Zool., 20, 55 (1967).

\section{STUMPTAIL BEHAVIOUR}

The Behavioral Repertoire of the Stumptail Macaque A Descriptive and Comparative Study. By Mireille Bertrand. (Bibliotheca Primatologica, No. 11.) Pp. $\mathrm{xi}+273$. (Karger: 13asel and New York, 1969.) 122s; $\$ 14.65$.

This monograph describes in detail the behavioural repertoire of Macaca speciosa. Most of the information was obtained from observations of captive animalsusually ones living in groups in large eages. A brief field study allowed a few comparisons to be made with the behaviour of wild animals, and in some cases comparisons are made with the behaviour of other primate species.

The first two chapters deal with the taxonomy and distribution of stumptails, and with the materials and methods used in the study. The next chapter presents quantitative data on the proportion of time spent in various occupations (for example, feeding, grooming, locomotion) by the groups of eaptive animals. The group structure was manipulated so that the bchaviour of non-adults alone could be compared with that of nonadults in the presence of adults and vice versa. Not surprisingly there were differences, and furthermore a few observations on a wild group suggested that they differed from the captive ones.

The following seven chapters each contain detailed descriptions of different types of behaviour. It is unfortunate that the criteria for the assignment of patterns or groups of patterns between these chapters are not consistent. For instance, play is assigned as follows: locomotory play is with locomotion because some of the same motor patterns are involved (a descriptive criterion); rough-and-tumble play is with agonistic and friendly behaviour because of its comparability with agonistic behaviour and because of a similarity in function in establishing dominance (descriptive and functional eriteria); investigatory play is with watchful and alarm behaviour because they are elicited by the same kinds of environmental stimuli (a causal critcrion). The behavioural category "play" is undoubtedly too broad to be specially useful, particularly when function is being considered, but the subdivision of this or any other such category on variable criteria is no more than a hindrance.

The observations are, however, of high quality, and the details of the postures, facial expressions and vocalizations, and of the contexts in which they occur, provide a solid basis for comparison with other species. Furthermore, anybody who has the opportunity to study the species in the wild will be much helped by the descriptions in the book. The descriptions are well supported by good photographs, including sound spectrographs, and line drawings. Thero is a good bibliography but, unfortunately, no index.

\section{Obituaries}

\author{
Earl Russell
}

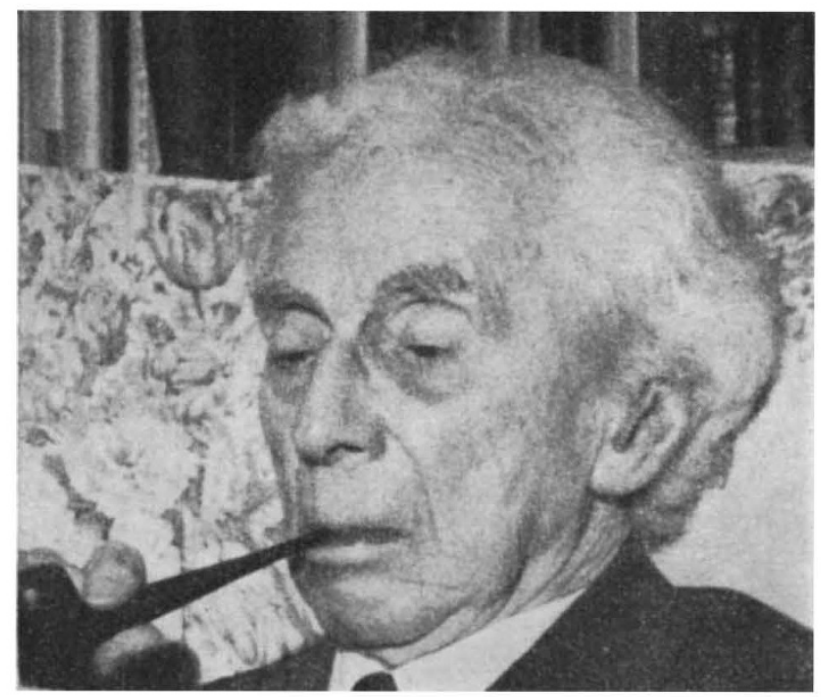

EARL Russell, OM, FRiS, died on February 3, 1970, at the age of 97 . As a philosopher in the widest and oldest sense of the word, he had the rare ability to communicate lucidly with Iayman and professional philosophor alike, and to extend the range of his interests consistently from symbolic logic to social involvoment. His intellectual scope included politics, the history of philosophy, mathematics and, not least, science.

Bertrand Russell's philosophy of science was very much a product of his wider philosophical and logical interests. After his pre-1900 abandonment of idealism, Russell became a logical realist and a pluralist. His analysis of science was dominated by two powerful maxims. The first was a determination to pursue a robustly realistic "common sense" attitude to those objects, both concrete and abstract, with which science deals. The "real" things in the world were not inextricably mental-the pervading orthodox view--but independent, individual things whose discovery and description required an analysis of human belief in order to find their correct form. These forms were to be expressed in simple or "atomic" propositions.

Pursuing this analysis in The Principles of Mathematics (1903) Russell was to find an overabundance of "real" things: "A man, a moment, a number, a class, a relation, a chimaera or anything else that can be mentioned"such an excess constituted a challenge to an orderly and disciplined mind. Nevertheless, his pursuit of this analysis placed and kept him firmly in the British empirieist tradition.

In the writing of his magnum opus, the celebrated Principia Mathematica, Russell developed the tochniques of "logical construction" of one entity from another which were to support his second maxim: "Whenever possible, substitute constructions out of known entities for inferences to unknown entities". Numbers become classes of classes of objects and later, in The Analysis of Matter (1927), objects became classes of events, which were constructed from classes of sense impressions.

Although a good deal of Russell's analysis of the content and validity of our knowledge of the world is conducted at an abstract level (as, for example, in Our Knowledge of the External World, 1914) he did not hesitate to plunge where necessary into a detailed analysis of current scientific theories. An example of this was The Analysis of Matter, 
in which he discussed the theory of quanta, special relativity, geodesics, invariants, differential equations, the theory of measurement and of space and time.

Perhaps his most direct influence on the philosophy of science has been in these applications of logical construe. tion and other symbolic techniques which first appeared in the Principia. Their effect on modern logic (and mathematics) has been incalculable. The success of this analytic approach moved many other philosophers, including the Vienna Circle group of logical positivists, to attempt similar projects in the physical sciences.

Much later in his career (Human Knowledge: Its Scope and Limits, 1948) Russell turned again to a sustained attack on the problems specifically related to science and provided a more modern analysis of a number of basic scientific concepts. In this work he presented his analysis of two problems that have been prominent in the philosophy of science: namely, the difficulty of providing a formally correct and materially adequate definition of the nature of probability statements, and the provision of a theory of non-deductive inferences as they are used in the sciences. In 1950 Russell was a founder member of the British Society for the Philosophy of Science.

Characteristically, Russell had no hesitation in attempting the difficult task of bridging the ever widening gap between philosophy and science. In writing The $A B C$ of Quanta (1923) and The $A B C$ of Relativity (1924) he presented, perhaps somewhat idiosyncratically, the fruits of modern science predigested for philosophers, and demonstrated the benefits of analytic philosophy in a manner palatable to scientists. A Herculean task?

Beyond his philosophy of science, Russell was an indefatigable popularizer of science and an exponent of the application of scientific method to the solving of social, political, moral and philosophical problems. Our Know. ledge of the External World was subtitled "As a field for Scientific Method in Philosophy". He was undoubtedly among the pioneers who called for social responsibility on the part of scientists and he acted accordingly, in repeatedly analysing the impact of science and technology on society.

Perhaps some insight into the source of Russell's continuing influence is found in the concluding paragraph of Human Knowledge. "In this sense, it must be admitted, empiricism as a theory of knowledge has proved inadequate, though less so than any other previous theory of knowledge. Indeed, such inadequacies as we have seemed to find in empiricism have been discovered by strict adherence to a doctrine by which empiricist philosophy has been inspired: that all human knowledge is uncertain, inexact and partial. To this doctrine we have not found any limitation whatever."

\section{Correspondence}

\section{Can a Scientific Article be Libellous?}

Sir,-In a case before the Court of Appeal, reported in The Times (February 13, 1970), a dental surgeon was given leave to take libel action against the British Medical Association and others. The Court held that "a scientific paper in the British Medical Journal which was critical of a technique for dental anaesthesia introduced, used and recommended [previously in the same journal] by a named dental surgeon was held by a majority of the Court to be capable of bearing a meaning defamatory of the surgeon in the way of his profession and that it should not therefore be struck out in limine as disclosing no reasonable cause of action". While the judges avoided implications as to the likely outcome of such action in court, they maintained that a suit for libel was justified. As suggested in the dissenting judgment by the Master of the Rolls, Lord Denning, the ramifications of this decision on the scientific world could be serious.

The central issue in the majority judgment was expressed by Lord Pearson, who was reported as saying that "the author's name, practice and reputation have been and were closely associated with the technique in question". Therefore, an attack on the technique held forth the possibility of being an attack on the author and must be entered to jury-decision. In suits claiming libel, the defendant must prove to a jury's satisfaction that his actions did not constitute a personal, subjective defamation of the plaintiff. However, the cost in time and funds to prepare a case to the satisfaction of a lay-jury could be prohibitive to many research efforts and personally ruinous to the defendant.

The Master of the Rolls was reported as expressing that "it would be a sorry day if scientists were to be deterred from publishing their findings for fear of libel actions. So long as they refrained from personal attacks, they should be free to criticize the systems and techniques of others. It was in the interest of truth itself. Were it otherwise, no scientific journal would be safe". On the basis of the judgment in this case, allowing the libel action to proceed, there is clearly cause for concern for all of us. Within the scientific community one accepts that criticism is given and taken. While reputations may be enhanced or damaged in this manner, it rarely becomes a legal issue. However, individual criticism of any research involving commercial interests would appear now to be open to the risk of expensive libel action.

\author{
Yours faithfully, \\ JoHN R. LEWIS \\ JOHN S. GRAY \\ Leland W. Pollock \\ P. GeOFFrey Moore
}

Wellcome Marine Laboratory,

University of Leeds,

Robin Hood's Bay,

Yorkshire.

\section{Should Slides be Seen Blind?}

SIR,-The suggestion is in the wind that, in the safety evaluation of drugs and potential food additives, histopathological material derived from studies on animals should be examined "blind"; that is to say, by a pathologist who is not told which material is derived from treated animals and which from untreated controls. If this suggestion is being seriously put forward, and if it applies to the first time that slides are to be examined, then we believe it to be ill-advised.

The pathologist's appraisal of toxicity should begin with a consideration of the overall design of the experiment and of details of mortality and morbidity in animals subjected to each form of treatment. Next he should acquaint himself with the clinical history of each animal. Central to his appraisal will be observations made by the naked eye at necropsy. Subsequent microscopic examination of material taken for histopathology may or may not add to the information already gained; but it is more likely to do so if detailed clinical and post mortem reports are available to the pathologist at the time he examines the slides. In any case, unless he has these reports before him, he cannot be sure that the microtome knife has found all the lesions seen macroscopically, and he may be in doubt as to the exact location and size of lesions. This description is nothing more than a statement of the general principles of sound pathological practice as they apply to the special problems associated with the safet: evaluation of drugs and other agents.

Many variables face the pathologist as he examines histological material from toxicity studies. It would be impracticable for him to consider all of them. Awareness 